\title{
Does building activity influence web construction and web characteristics in the orb-web spider Zygiella x-notata (Araneae, Araneidae)?
}

\author{
Alain Pasquet $^{1 *}$, Julia Marchal ${ }^{2}$, Mylène Anotaux ${ }^{1}$ and Raymond Leborgne ${ }^{1}$
}

\begin{abstract}
Background: Very few studies have investigated the influence of regular practice of a stereotyped behaviour on its future expression. In spiders, orb-web construction is a succession of repetitive and stereotyped behaviours and is a relevant model for such study. This study examined if preventing spiders from building influences their future constructions.

Spiders were caught in the field and brought back to the laboratory where they were exposed to two different situations; half were maintained in small boxes where web building was not possible, and half were maintained in large enclosures where they could build orb-webs. All spiders were tested twice: 1 week after their capture (test 1) and 12 weeks later (test 2). Their building performance was evaluated by examining silk investment (length of the capture spiral, number of radii, of spiral turns, length of the lower part of the web), web design (mesh height, asymmetry) and the frequency of anomalies in the web.
\end{abstract}

Results: There was no difference in web constructions between the two groups in either test. However, the rearing conditions seemed to affect two parameters: the length of the lower part of the web and the asymmetry were higher for spiders reared in small boxes. We did find also, an overall decrease with time in silk investment (length of the capture spiral, capture area) in both groups as well as an increase in the number of anomalies of the capture spiral from tests 1 to 2 .

Conclusions: These results suggest that regular web construction does not have a strong effect on web structure or silk investment, but spider age did affect parameters in the two groups. Thus, the lack of practice over a large portion of a spider's adult life does not affect a stereotyped behaviour such as the building of an orb-web.

Keywords: Stereotyped behaviours; Experience; Spiders; Web characteristics

\section{Background}

Lorentz (1937) defined the term stereotyped behaviours, as 'repetitive, predictive motor patterns'. Stereotypy has recently been used to describe behaviours that show low variation (Nishikawa 2000; Deban et al. 2001) or that do not vary in response to environmental changes (i.e. prey type, Mattot et al. 2005; Wainwright and Lauder 1986). In general, stereotyped behaviours have been mostly described and studied in invertebrates, and one of the best examples is the web building behaviour of the orb-web spiders (Peters 1939a, b; Witt and Reed 1965; Vollrath

\footnotetext{
* Correspondence: alain.pasquet@univ-lorraine.fr

${ }^{1}$ Faculté des Sciences et Technologies, Université de Lorraine, BP 239,

Vandoeuvre les Nancy Cedex 54506, France

Full list of author information is available at the end of the article
}

and Mohren 1985). In this context, the question is, can some form of pretreatment of an individual modify the outcome of a stereotyped behaviour? To answer this question, web construction by orb-weaver spiders appears to be a good model.

In orb-weaver spiders, web building behaviour follows three distinct phases: construction of the frame and radii, weaving of an auxiliary spiral and weaving of the sticky or capture spiral (Foelix 2011). To weave the capture spiral, the spider starts at the periphery and uses the auxiliary spiral as a guide. During this phase, the spider's legs play an important role (Vollrath 1987a). The spider advances step by step to produce the sticky spiral while maintaining the distance between successive turns equally (Vollrath and Mohren 1985). Thus, completion 
of the capture spiral results from successive and repetitive actions, which is the definition of stereotyped behaviour.

In this context, juvenile spiders build webs as regular as those of adults: they do not need to learn (Reed et al. 1970). In species where differences were found between the juvenile and adult webs (Szlep 1961; Burch 1979; Sensenig et al. 2011), adult webs were less regular and symmetrical than those of juveniles, which could be due not only to an increase in spider weight during growth (Venner et al. 2003; Venner and Casas 2005) but also in changes of diet during development (Sensenig et al. 2011). However, we cannot conclude that web building is entirely stereotyped; the highly regular structure of a geometrical web can show some variability (Eberhard 2007, 2011; Harmer et al. 2011; Barrantes and Eberhard 2012; Hesselberg 2013) and can be altered (Vollrath and Mohren 1985; Vollrath et al. 1997; Coslovsky and Zschokke 2009). These changes can be caused not only by environmental factors (wind, vegetation supports, prey) (Heiling and Herberstein 2000; Liao et al. 2009), but also by spider behaviour during construction (Eberhard and Hesselberg 2012; Toscani et al. 2012). For example, if a spider has a regenerated leg, the structure of the web may be modified (Vollrath 1987a) but without altering its prey capture efficiency (Pasquet et al. 2011). Some elements of symmetry and regularity in the web also changed due to environmental conditions (Harmer and Herberstein 2009; Kuntner et al. 2010a, b; Nakata 2010; Nakata and Zschokke 2010; Gregoric et al. 2013) and age (Anotaux et al. 2012) or when spiders were under the influence of drugs (Witt et al. 1968; Hesselberg and Vollrath 2004), Whether the building conditions are natural or in the laboratory may also affect the amount of silk invested in the web and web design (Sensenig et al. 2010).

Since the construction of orb-webs can be considered as a perfect model resulting from a succession of fixed and repetitive behaviours, it is relevant to test the effect of a pretreatment on future constructions; does the fact that an orb-weaving spider did not build a web for a long period of time affect its future web building? This is relevant because some orb-web spiders spend several months without being able to build a web during winter. This is the case in the Palaearctic countries, where spiders spend winter as adult or sub-adults and do not make a web.

Web construction involves motor activity and cognitive ability (i.e. threads are deposited according to the presence of previous threads; Vollrath and Mohren 1985; Eberhard and Hesselberg 2013). Changes associated with web geometrical structures have been observed at two different levels: changes that affected the global design of the web, which are generally measured by variations in web symmetry (Hesselberg 2013; Eberhard and Hesselberg 2012), and changes that affected the web at a finer level involving the deposition of each thread segment (Toscani et al. 2012; Pasquet et al. 2013).

Spider web building may change with building experience. In this context, web structure may be less perfect for spiders without the opportunity to regularly make webs (prevented from weaving) compared to webs made by spiders that regularly build webs. The European species, Zygiella $x$-notata is a good candidate for such a study: this species reproduces in autumn, but some adult or subadult females do not reproduce and spend winter in holes in the walls outside buildings (Bel-Venner and Venner 2006). During this period, the spiders do not build a web; their next construction will take place at the beginning of spring, so they do not practice web construction behaviours for several months. In this study, we tested the hypothesis that a pretreatment with regular web building activity may improve web building behaviour.

\section{Methods}

\section{Spiders}

Zygiella $x$-notata (Clerck) is an orb-weaving spider common in Europe. This medium-sized spider (females 5.5 to $8 \mathrm{~mm}$ and males 3 to $5 \mathrm{~mm}$, Roberts 1995) has an annual life cycle, with the adults present at the end of summer and in autumn, but in some cases, sub-adult or adult females may otherwise survive the winter. Females lay egg sacs in autumn, and juveniles develop in the following spring. We collected sub-adult females in August and September and brought them back to the laboratory. They were fed with one fly (Lucilia caesar) and sprayed with water once a week. All spiders were examined every day to determine their developmental status: as they were collected as sub-adults, most moulted in the laboratory. Their age was noted as zero when they moulted. As they were maintained in laboratory conditions, we monitored their death date so as to determine their lifespan under the rearing conditions.

\section{Protocol design}

After moulting, all spiders were put into large frames $(50 \times 50 \times 10 \mathrm{~cm})$ where they built a web. This is referred to as test 1 (T1). Next, half of the spiders (sample B for the box group $n=112$ ) were randomly chosen and placed into small boxes $(10 \times 7 \times 2 \mathrm{~cm})$ where they could not build a web. The other half (sample $F$ for the frame group $n=111$ ) were put into large frames. In each sample, spiders were fed with two flies (L. caesar) and sprayed with water once a week. Twelve weeks later, all living spiders (sample $\mathrm{B}, n=82$; sample $\mathrm{F}, n=75$ ) were put into large frames for test 2 (T2). During the tests (T1 and T2), the spiders were not fed, and there was no fly in the frames. Spiders were weighed before each test (Sartorius balance, Aubagne Cedex, France; $0.1 \mathrm{mg}$ ). 
For each test (T1 and T2), spiders (samples B and F) were put into large frames for a 72 -h period. For spiders of both groups, we considered only the first web built. Webs built in T1 and T2 by each spider were measured and photographed (Panasonic DMC-FZ18, Osaka, Japan) using a black background behind the web and an artificial white light. All the photographs were transformed into a negative picture (Photofiltre Software 7.0.1) to give a black silky thread on a white background.

\section{Parameters}

\section{Web characteristics}

Web structure (Figure 1) was considered at three different levels: investment in silk, general shape and anomalies in the capture spiral. The investment is measured by the length of the capture thread (CTL) (for formula, see Venner et al. 2001) and by the capture area (CA) (for formula, see Venner et al. 2001), which represents the surface of the web minus the surface of the free sector (sector without spiral thread, characteristic of some Zygiella webs); the number of radii was noted for each web. Zygiella webs are asymmetrical; the lower part beneath the centre is larger than the upper part. We characterised the general shape by the asymmetry of each web by measuring the ratio between the length of the part above the centre and the length of the part below the centre. We added parameters to characterise the lower part of the web located under the centre, which is, for this species, the most important area for foraging activity (Nakata and Zschokke 2010).
These parameters were the length of this lower part measured as the distance between the outermost and innermost spiral turns and the number of spiral turns. In this lower part of the web, mesh height was calculated by dividing the length of the lower part by the number of turns minus one.

\section{Web anomalies}

Anomalies (for definition, see Pasquet et al. 2013) were counted from the web photos. Anomalies are faults in the geometrical structure. They can affect the radii or the capture spiral. Three anomalies were concerned with the radii, and seven were concerned with the capture spiral, which was delimited by the innermost and outermost spiral turns. The capture spiral can be considered as a succession of threads joining two radii that we call spiral units. As the number of anomalies in a web depends on the total number of spiral units deposited by the spider (Pasquet et al. 2013), we calculated the ratio of anomalies (A) per metre of length of the capture thread (A/CTL).

\section{Statistical analysis}

We used a chi-square $\left(X^{2}\right)$ test to compare web building in the two groups (sample B vs sample F) in T1 and T2. A Kolmogorov-Smirnov goodness of fit test was applied to determine whether the sample data were likely to derive from a normally distributed population. When the data did not fit normality, we applied a log transformation (the

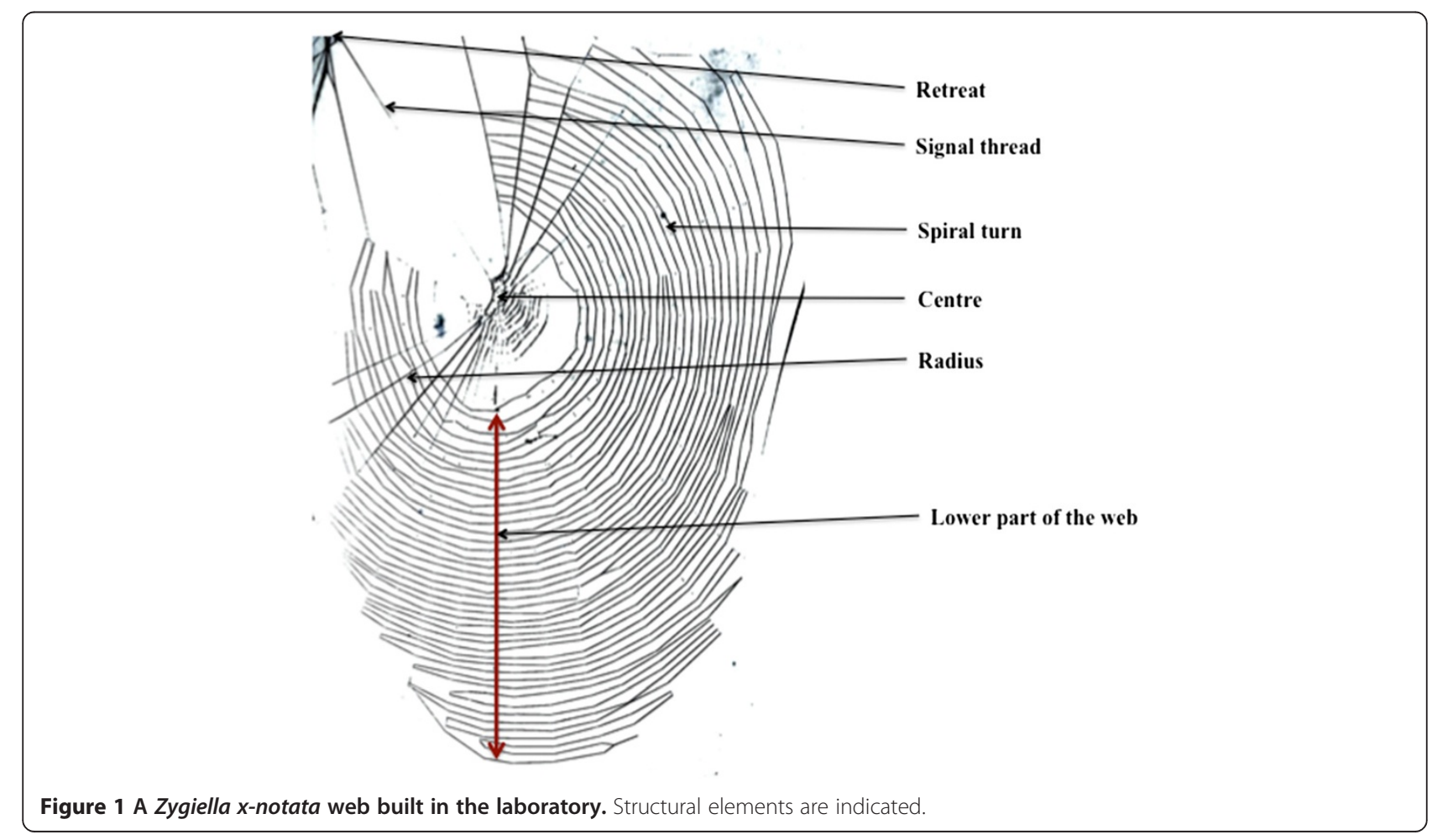


following parameters were concerned: CTL, CA, number of radii, parameters of the lower part of the web). The influence of the rearing conditions (sample B vs sample F and $\mathrm{T} 1 \mathrm{vs} \mathrm{T} 2$ ) on all web parameters was analysed with analysis of covariance (ANCOVA) using T1 data as covariate. To compare spider longevity, weight and web parameters between $\mathrm{T} 1$ and $\mathrm{T} 2$, we used a $t$ test for paired data and only used the spiders that built a web in both tests ( $n=25$ for each sample). We used a $t$ test for non-paired data to compare weight, longevity and web parameters between the samples B and F. Significance was considered at $p<0.05$. Statistical tests were conducted with Statview Software (5.0) on a Macintosh platform.

\section{Results and discussion Results}

Comparison of spider longevity and spider mass between the two rearing conditions

Longevity differed between the spiders of the two groups ( $\mathrm{B}$ and $\mathrm{F}$ ); spiders in boxes (B) had lived longer than those in the frames (F) (sample B, 146 days $\pm 44(n=82)$ and sample F, 128 days $\pm 47(n=60) ; t$ test: $t_{141}=2.35$, $p=0.02$ ). There was no difference in spider weight between samples B and F in either T1 (sample B: $m=30.9$, $\mathrm{SD}=8.6 \mathrm{mg}, n=20$ and sample $\mathrm{F}: m=30.6, \mathrm{SD}=8.9 \mathrm{mg}$, $n=18$; $t$ test: $t_{36}=0.12, p=0.90$ ) or T2 (sample B: $m=31.6$, $\mathrm{SD}=9.3 \mathrm{mg}, n=20$ and sample $\mathrm{F}: m=29.7, \mathrm{SD}=15.6 \mathrm{mg}$, $n=18$; $t$ test: $t_{36}=0.45, p=0.65$ ). There was no weight variation between $\mathrm{T} 1$ and $\mathrm{T} 2$, either for spiders in sample B ( $t$ test for paired data: $t_{19}=0.26, p=0.79$ ) or in sample $\mathrm{F}\left(t\right.$ test for paired data: $\left.t_{17}=0.26, p=0.80\right)$.

\section{Variation in web building and web characteristics in each sample}

Sample B Our analysis showed that for webs built in T1 and T2 $(n=25)$, the differences between web parameters were significant (Student's $t$ test for paired data; Table 1) for all the parameters except for the number of radii, the mean inter-spiral turn distance in the lower part of the web and the asymmetry. There was a decrease in silk investment (CTL, capture area, length and number of spiral turns in the lower part of the web), with no difference in mesh height, and an increase in anomaly number (A/CTL) (Table 1).

Sample F Comparison between webs built in T1 and T2 for sample $\mathrm{F}(n=25)$ showed significant differences for all parameters except for the inter-spiral turn distance in the lower part of the web ( $t$ test for paired data; Table 2). There was a decrease in silk investment (CTL, capture area, number of radii, length of the lower part of the web), with no difference in mesh height, and an increase
Table 1 Mean (SD) of parameters measured or calculated on webs built by the spiders reared in boxes

\begin{tabular}{lccc}
\hline Parameters & \multicolumn{2}{c}{ Mean (SD) } & \multirow{2}{*}{ test $(\boldsymbol{p})$} \\
\cline { 2 - 3 } & Test 1 & Test 2 & \\
\hline Length of the spiral thread $(\mathrm{cm})$ & $520(25)$ & $373(29)$ & $4.22(<0.001)$ \\
Surface of the capture area $\left(\mathrm{cm}^{2}\right)$ & $114(11)$ & $98(12)$ & $4.02(<0.001)$ \\
Asymmetry & $0.3(0.03)$ & $0.26(.03)$ & $1.28(0.21)$ \\
Number of radii & $26(1)$ & $24(1)$ & $1.27(0.22)$ \\
Length of the lower part $(\mathrm{cm})$ & $8.5(0.5)$ & $6.1(0.4)$ & $3.54(0.002)$ \\
Number of spiral turns & $31(1)$ & $26(2)$ & $2.39(0.025)$ \\
Mesh height (mm) & $2.7(0.2)$ & $2.7(0.2)$ & $0.34(0.74)$ \\
Anomaly ratio (A/CTL) & $8(0)$ & $16(2)$ & $4.34(<0.001)$ \\
\hline
\end{tabular}

Comparisons were made between tests 1 and 2 ( $t$ test for paired data, $n=25$ ). Italicised characters indicate that the difference is significant at least at $p<0.05$.

in the anomaly number (A/CTL). The asymmetry decreased between the two tests (Table 2).

\section{Comparison of the two samples}

The number of spiders that spun a web did not differ between the two samples either in T1 (sample $\mathrm{B}=78 \%$ vs sample $\mathrm{F}=83 \%, X_{1}^{2}=0.66, p=0.41$ ) or $\mathrm{T} 2$ (sample $\mathrm{B}=$ $54 \%$ vs sample $\mathrm{F}=55 \%, X_{1}^{2}=1.30, p=0.25$ ). ANCOVA, using the T1 data as covariate for each parameter, was carried out to separate the influence of spider rearing conditions from the effect of time. Twenty-five spiders in the two groups were taken into account in this analysis. The results showed that the following parameters had no influence regardless of rearing conditions: CTL $(F=2.3, p=0.13)$, CA $(F=1.5 ; p=0.22)$, number of radii $(F=2.7, p=0.10)$, number of spiral turns in the lower part of the web $(F=0.0, p=0.87)$ and A/CTL $(F=0.0$, $p=0.88)$. There were two parameters which showed significant variation: length of the lower part of the web $(F=5.9$, $p=0.02)$ and the asymmetry $(F=9.1, p=0.004)$; mesh

Table 2 Mean (SD) of parameters measured or calculated on webs built by the spiders reared in frames

\begin{tabular}{lccc}
\hline Parameters & \multicolumn{2}{c}{ Mean (SD) } & \multirow{2}{*}{ test $(\boldsymbol{p})$} \\
\cline { 2 - 3 } & Test $\mathbf{1}$ & Test $\mathbf{2}$ & \\
\hline Length of the spiral thread $(\mathrm{cm})$ & $492(40)$ & $358(32)$ & $5.05(<0.001)$ \\
Surface of the capture area $\left(\mathrm{cm}^{2}\right)$ & $132(12)$ & $86(12)$ & $6.58(<0.001)$ \\
Asymmetry & $0.29(0.02)$ & $0.19(0.02)$ & $3.30(0.004)$ \\
Number of radii & $25(1)$ & $22(1)$ & $3.29(0.004)$ \\
Length of the lower part $(\mathrm{cm})$ & $8.4(0.5)$ & $5.7(0.4)$ & $6.24(<0.001)$ \\
Number of spiral turns & $30(2)$ & $25(2)$ & $2.08(0.049)$ \\
Mesh height (mm) & $2.6(0.1)$ & $2.3(0.2)$ & $1.43(0.165)$ \\
Anomaly ratio (A/CTL) & $8(0)$ & $12(1)$ & $3.39(0.002)$ \\
\hline
\end{tabular}

Comparisons were made between tests 1 and 2 ( $t$ test for paired data, $n=25$ ). Italicised characters indicate that the difference is significant at least at $p<0.05$. 
height in the lower part of the web showed a strong ten$\operatorname{dency}(F=3.0, p=0.06)$.

\section{Discussion}

Intra-individual variability in orb-web characteristics exists at different levels: silk investment, which is represented by the length of the thread that the spider produces (length of the spiral thread and number of radii) and web design characteristics (asymmetry, length of the lower part of the web and anomalies).

In general, the design and characteristics of the web are known to vary with environmental or internal conditions. Web structure can be affected by gravity (Witt et al. 1968, 1977; Vollrath and Mohren 1985), the absorption of drugs (Witt and Reed 1965; Reed and Witt 1968; Hesselberg and Vollrath 2004) or a morphological disability (missing or shorter leg) (Vollrath 1987b; Pasquet et al. 2011). Furthermore, studies showed that web characteristics show variation at the intra-specific and intra-individual level (Herberstein and Heiling 1999; Heiling and Herberstein 1999), and it is known that web structure is the direct reflection of spider behaviour (Zschokke and Vollrath 1995).

The first result of our study is that spider rearing conditions do not affect their weight; spider development in boxes and large frames was the same. One explanation could be that we tested virgin females, and their energetic needs are very different to those of reproducing females, but in the field, most Zygiella, which survived winter conditions, were sub-adult females (Bel-Venner and Venner 2006). As we know that weight can influence web characteristics due to gravity (Venner and Casas 2005), we could disregard the spider weight when examining the differences between the webs of the two groups of spiders.

Our results showed that rearing conditions had no effect on the spider's investment in silky structures; there was no difference in the length of the thread used in web construction, and thus, there was no difference in the capture area surface or the number of spiral turns in the lower part of the web. Thus, regardless of rearing conditions and the spider's experience in orb weaving, they did not modify the amount of silk invested in the web. It is known that spiders in natural conditions invest more than those in the laboratory (Sensenig et al. 2010), which could be linked to the fact that laboratory conditions are very poor, i.e. spiders do not have access to as many prey as in the field. We can conclude that the lack of practice of the stereotyped behaviours involved in the web construction had no effect on the final orb. In these conditions, we showed that we could breed numerous spiders in a small space and test their orb-web construction in larger enclosures with few consequences on the orb-web characteristics. This result validates studies in laboratory testing the effects of environmental or physiological factors on web characteristics.
The second interesting result of this study is that web asymmetry was affected by the rearing conditions; the spiders reared in boxes spun webs with greater asymmetry than the spiders that were reared in frames and had the opportunity to make webs whenever they wanted. In fact, the spiders in frames increased the symmetry of their webs between the two tests (T1 and T2). Asymmetry is one of the ways spiders enlarge their web's capture area. It is a response to the spider's physiological state (i.e. there are differences between asymmetry in webs depending on development; juvenile webs are more symmetric than adult webs Sensenig et al. 2011) or prey (i.e. prey size, Blamires et al. 2010) constraints. It is more efficient to enlarge the lower part of the web because it is easier to catch prey in this region than in other parts of the web due to gravity (Venner and Casas 2005; Kuntner et al. 2010b). This is also an adaptation to environmental structural constraints (Kuntner et al. 2010a; Hesselberg 2013), and this enlargement without increasing silk investment but by increasing mesh height could be interpreted in terms of optimal foraging; it is better for a spider to enlarge this part of its web where prey capture is more efficient (Gregoric et al. 2013). Thus, the spiders reared in boxes have a more similar building behaviour to spiders in the field; it seems that spiders in the frames adapt their web (with a greater symmetry) to the situation where they get regular food.

The third result from this study was the absence of a difference in the number of anomalies between the webs weaved by the spiders in the two groups. As anomalies are directly linked to behaviour during web construction (Foelix 2011), we could expect that the number of anomalies would increase for the spiders reared in boxes, but this was not the case. These results are in agreement with the previous study by Sensenig et al. (2010) that found that the general design of the web structure was not affected when webs were built under natural conditions (fence) or in the laboratory. Anomalies have not been extensively studied for orb-webs; they were rather unevaluated in experiments where spiders were put in extreme conditions such as weightlessness (Witt et al. 1968), drugs (Witt and Reed 1965; Hesselberg and Vollrath 2004), feeding (Blamires 2010) and ageing (Anotaux et al. 2012). Anomalies are difficult to use as parameter as they are numerous and varied (Pasquet et al. 2013). This phenomenon is also very difficult to study under natural conditions: after construction, the geometrical design of an orb-web is never perfect in the field. As soon as a web is made, or even during construction, the structure may be damaged by external events (wind, insects, vegetal). Indeed, under these conditions, it is difficult to determine whether an anomaly is the consequence of behavioural variation or due to external events. Previously, we showed that under laboratory conditions, anomalies in the orb structure are due to spider behavioural sequences during the capture spiral 
construction (Toscani et al. 2012). However, in this present study, experience had no influence on the number of anomalies made during web construction. We can therefore conclude that the behavioural scheme for web building is not affected by experience.

\section{Conclusions}

In this paper, we asked this the question: had some form of pretreatment of an individual modified the outcome of a stereotyped behaviour? To answer this question, web construction by orb-weaver spiders appeared to be a good model. The orb-web is the result of a succession of stereotyped behaviours, and on the other hand, it is known that many environmental perturbations could lead to variations in web characteristics. Our study under laboratory conditions showed three main points: (1) the web building and the orb design of the web were not affected by the absence of building practice by the spiders, (2) there were some fine adjustments to the experimental situation and (3) these latter results were dependent of the spider's age. An interpretation of these results is that components of the stereotyped behaviour involved in web construction in orb-web spiders are robust and not influenced by the experience of the spider, but as we can find in the literature, the orb-web is a plastic object, which can adapt to environmental or individual conditions. This behavioural duality (stereotypy and adaptation) is the main result of our study and shows that it is necessary to introduce a pertinent choice of the web parameters in all studies on orb-webs.

\section{Competing interests}

The authors declare that they have no competing interests.

\section{Authors' contributions}

AP conceived the study, coordinated it, analysed the data and wrote an early draft of this manuscript. JM carried out the experimentations to obtain the data. MA participated in the collection of the data. RL conceived the study and participated in its design. All authors read and approved the final manuscript.

\section{Acknowledgements}

This work was supported by a grant from the 'Longevity and ageing' program of the CNRS and the University of Lorraine. We thank also L. Bahans for her technical help in breeding the spiders and carrying out experiments. We thank also Leigh Gebbie (LGK Australia) for her English language revision.

\author{
Author details \\ ${ }^{1}$ Faculté des Sciences et Technologies, Université de Lorraine, BP 239 \\ Vandoeuvre les Nancy Cedex 54506, France. ${ }^{2}$ Centre National de la \\ Recherche Scientifique, Muséum National d'Histoire Naturelle, UMR 7179, \\ Brunoy, France.
}

Received: 26 September 2013 Accepted: 6 February 2014 Published: 18 February 2014

\section{References}

Anotaux M, Marchal J, Chaline N, Desquilbet L, Leborgne R, Gilbert C, Pasquet A (2012) Ageing alters spider orb-web construction. Anim Behav 84:1113-1121, doi: 10.1016/j.anbeahv.2012.08.006
Barrantes G, Eberhard WG (2012) Extreme behavioral adjustments by an orb-web spider to restricted spaces. Ethology 118:438-449, doi: 10.1111/j1439- 0310.2012.02029.x

Bel-Venner ME, Venner S (2006) Mate-guarding strategies and male competitive ability in an orb-weaving spider: results from a field study. Anim Behav 71:1315-1322, doi: 10.1016/j.anbeahv.2005.08.010

Blamires SJ (2010) Plasticity in extended phenotypes: orb web architectural responses to variations in prey parameters. J Exp Biol 213:3207-3212, doi: 10.1242/jeb.045583

Blamires SJ, Chao IC, Tso IM (2010) Prey type, vibrations and handling interactively influence silk expression. J Exp Biol 213:3906-3910, doi: 10.1242/jeb.046730

Burch TL (1979) The importance of communal exposure to survival for spiderlings of Araneus diadematus. J Arachnol 7:1-18

Coslovsky M, Zschokke S (2009) Asymmetry in orb-webs: an adaptation to web building costs. J Insect Behav 22:29-38, doi: 10.1007/s10905-008-9151-2

Deban SM, O'Reilly JC, Nishikawa KC (2001) The evolution of the motor control of feeding in amphibians. Am Zool 41:1280-1298

Eberhard WG (2007) Miniaturized orb-weaving spiders: behavioural precision is not limited by small size. Proc R Soc B 274:2203-2209, doi: 10.1098/rspb.2007.0675

Eberhard WG (2011) Are smaller animals behavioural limited? Lack of clear constraints in miniature spiders. Anim Behav 81:813-823, doi: 10.1016/j.anbeahv.2011.01.016

Eberhard WG, Hesselberg T (2012) Cues that spiders (Araneae: Araneidae, Tetragnathidae) use to build orbs: lapses in attention to one set of cues because of dissonance with others? Ethology 118:610-620, doi: 10.1111/j.1439-0310.2012.02048.x

Foelix RF (2011) Biology of spiders. Oxford University Press, Oxford

Gregoric M, Kiesbuy H, Quinones Lebron S, Rozman A, Agnarsson I, Kuntner M (2013) Optimal foraging, not biogenetic law, predicts spider orb web allometry. Naturwissenschaften 100:263-268, doi: 10.1007/s00114-013-1015-8

Harmer AMT, Herberstein ME (2009) Taking it to extremes: what drives extreme web elongation in Australian ladder web spiders (Aranidae: Telaprocera maudae)? Anim Behav 78:499-504, doi: 10.1016/j.anbeahv.2009.05.023

Harmer AMT, Blackledge TA, Madin JS, Herberstein ME (2011) High-performance spider webs: integrating biomechanics, ecology and behaviour. J R Soc Interface 8:457-471, doi: 10.1098/rsif.2010.1454

Heiling AM, Herberstein ME (1999) The role of experience in web-building spiders (Araneidae). Anim Cogn 2:171-177

Heiling AM, Herberstein ME (2000) Interpretations of orb-web variability: a review of past and current ideas. Ekol CSSR 19:97-106

Herberstein ME, Heiling AM (1999) Asymmetry in spider orb web (Araneidae): a result of physical constraints? Anim Behav 58:1241-1246, doi: 10.1006/anbe.1999.1255

Hesselberg T (2013) Web-building flexibility differs in two spatially constrained orb spiders. J Insect Behav 26:283-303, doi: 10.1007/s10905-012-9337-7

Hesselberg T, Vollrath F (2004) The effect of neurotoxins on web-geometry and web-building behaviour in Araneus diadematus Cl. Physiol Behav 82:519-529, doi: 10.1016/j.Physbeh.2004.04.058

Kuntner M, Gregoric M, Li D (2010a) Mass predicts web asymmetry in Nephila spiders. Naturwissenschaften 97:1097-1105, doi: 10.1007/s00114-010-0736-1

Kuntner M, Kralj-Fiser S, Gregoric M (2010b) Ladder webs in orb-web spiders: ontogenetic and evolutionary patterns in Nephilidae. Biol J Linn Soc Lond 99:849-866, doi: 10.1111/j.1095-8312-2010.1414.x

Liao CP, Chi KJ, Tso IM (2009) The effect of wind on trap structural and material properties of a sit-and-wait predator. Behav Ecol 20:1194-1203, doi: 10.1093/behave/arp119

Lorentz K (1937) Uber die Bildung des Instinkbegriffes. Naturwissenschaften 25:289-300

Mattot MP, Motta PJ, Hueter RE (2005) Modulation in feeding mechanisms and motor pattern of the nurse shark Gynclimostoma cirratum. Environ Biol Fishes 74:163-174

Nakata K (2010) Does ontogenetic change in orb-web asymmetry reflect biogenetic law? Naturwissenschaften 97:1029-1032, doi: 10.1007/s00114-010-0719-2

Nakata K, Zschokke S (2010) Upside-down spiders build upside-down orb-webs: web asymmetry, spider orientation and running speed in Cyclosa. Proc R Soc Lond B Biol Sci 277:3019-3025, doi: 10.1098/rspb.2010.0729

Nishikawa KC (2000) Feeding in frogs. In: Schwenk K (ed) Feeding: form, function and evolution in Tetrapod Vertebrates. Academic Press, San Diego, pp 117-147

Pasquet A, Anotaux M, Leborgne R (2011) Loss of legs: is it or not a handicap for an orb- weaving spider? Naturwissenschaften 98:557-564, doi: 10.1007/s00114-011-0799-7 
Pasquet A, Marchal J, Anotaux M, Leborgne R (2013) Imperfections in a perfect architecture: the spider orb web. Eur J Entomol 110:493-500

Peters HM (1939a) Uber das Kreuzspinnennetz und seine Probleme. Naturwissenschaften 47:477

Peters HM (1939b) Probleme des Kreuzspinnennetz. Z Morpho Oekologie Tiere $36: 179$

Reed CF, Witt PN (1968) Progressive disturbance of spider web geometry caused by two sedative drugs. Physiol Behav 3:119-124

Reed CF, Witt PN, Scaboro MB, Peakall DB (1970) Experience and the orb web. Dev Psychobiol 3:251-265

Roberts MJ (1995) Collins field guide: spiders of Britain and Northern Europe. Delachaux and Niestlé, S.A, Paris

Sensenig A, Agnarsson I, Gondek T, Blackledge TA (2010) Webs in vitro and in vivo: spiders alter their orb-web spinning behavior in the laboratory. J Arachnol 38:183-191

Sensenig A, Agnarsson I, Blackledge TA (2011) Adult spiders use tougher silk: ontogenetic changes in webs architecture and silk biomechanics in the orb-weaver spiders. J Zool 285:28-38, doi: 10.1111/j.1469.7998.2011.00809.x

Szlep R (1961) Some differences in the running pattern in two families Uloboridae and Argiopidae. Bulletin of the Research Council of Israel 9B1, Jerusalem

Toscani C, Leborgne R, Pasquet A (2012) Analysis of web building anomalies in the orb weaving spider Zygiella $x$-notata (Araneae, Araneidae). Arachnol Mitt 43:79-83

Venner S, Casas J (2005) Spider webs designed for rare but life-saving catches. Proc R Soc B 272:1587-1592, doi: 10.1098/rspb.2005.3114

Venner S, Tevenard L, Pasquet A, Leborgne R (2001) Estimation of the web's capture thread length in orb-weaving spiders: determining the most efficient formula. Entomological Society of America 90:490-496

Venner S, Bel-Venner MC, Pasquet A, Leborgne R (2003) Body mass-dependent cost of web- building behaviour in an orb-weaving spider Zygiella $x$-notata Naturwissenschaften 90:269-272, doi: 10.1007/s00114-003-0420-9

Vollrath F (1987a) Altered geometry of webs in spiders with regenerated legs. Nature 328:247-248

Vollrath F (1987b) Growth, foraging and reproductive success. Ecophysiology of spiders. Springer, Berlin, pp 57-70

Vollrath F, Mohren W (1985) Spiral geometry of the garden spider's orb web. Naturwissenschaften 72:666-667

Vollrath F, Downes M, Krackow S (1997) Design variables in web geometry of an orb-weaving spider. Physiol Behav 62:735-743

Wainwright PC, Lauder GV (1986) Feeding biology of sunfishes: patterns of variation in the feeding mechanism. Zool J Linn Soc 88:217-228

Witt PN, Reed CF (1965) Spider-web building. Science 149:1190-1197

Witt PN, Reed CF, Peakall DB (1968) A spider's web, problems of regulatory biology. Springer, New York

Witt PN, Peakall DB, Gause RL (1977) Spider web building in outer space; evaluation of records from the Skylab spider experiment. J Arachnol 4:115-124

Zschokke S, Vollrath F (1995) Unfreezing the behaviour of two orb spiders. Physiol Behav 58:1167-1173

doi:10.1186/1810-522X-53-11

Cite this article as: Pasquet et al:: Does building activity influence web construction and web characteristics in the orb-web spider Zygiella x-notata (Araneae, Araneidae)? Zoological Studies 2014 53:11.

\section{Submit your manuscript to a SpringerOpen ${ }^{\circ}$ journal and benefit from:}

- Convenient online submission

- Rigorous peer review

- Immediate publication on acceptance

- Open access: articles freely available online

- High visibility within the field

- Retaining the copyright to your article

Submit your next manuscript at $\gg$ springeropen.com 